\title{
Formation of Psychological Readiness of the Teacher to Implement Information and Communication Technologies in Professional Activities
}

\author{
${ }^{1}$ Liudmyla Honchar, ${ }^{2}$ Olga Derkachova, ${ }^{3}$ Valentyna Shakhrai, ${ }^{4}$ Volodymyr Saienko, \\ ${ }^{5}$ Olexandr Hladoshchuk, ${ }^{6}$ Tatiana Voropayeva, \\ ${ }^{1}$ Laboratory of Institutional Upbringing, Institute of Problems on Education of the National Academy \\ of Educational Sciences of Ukraine, Kyiv, Ukraine \\ ${ }^{2}$ Department of Primary Education Pedagogy, Vasyl Stefanyk Precarpathian National University, \\ Ivano-Frankivsk, Ukraine \\ ${ }^{3}$ Laboratory of Institutional Education, Institute of Problems on Education of the National Academy \\ of Educational Sciences of Ukraine, Kyiv, Ukraine \\ ${ }^{4}$ Faculty of Economics and Pedagogical, Academy of Management and Administration in Opole, \\ Opole, Poland \\ ${ }^{5}$ Department of Physical Education, Dniprovsky State Technical University, Kamiyanske, Ukraine \\ ${ }^{6}$ Faculty of Philosophy, Center for Ukrainian Studies, Taras Shevchenko National University of Kyiv, \\ Kyiv, Ukraine
}

Received: April 12, 2021. Revised: September 25, 2021. Accepted: October 10, 2021. Published: October 22, 2021.

\begin{abstract}
The relevance of discussing the components of the psychological strategy for teachers' use of Information and Communications Technology (ICT) at General High School Educational Institution (GHSEI) involves the categories of cooperation, reflexive, motivational and informational parts of the strategy have been developed and characterized as components of teacher readiness for professional activity in a multidisciplinary environment. The aim of the research is to develop a pedagogical strategy for psychological readiness of teachers to use ICT to eliminate internal and external barriers that interfere with the intensive exchange of information among and behind the educational team. Methodology. Sociological survey (number of participants 1200) on the platform "Online Test Pad" among teachers of GHSEI (Ukraine). Results. The list of components in the structure of psychological readiness of students to implementation of educational innovations, including emotional-motivational, cognitive-motivational, orientational, activity-operational, moral, communicative, volitional, mobilizing, evaluative-resulting. The article outlines the stages of solving the main psychological barriers to innovation in the use of information and communication technologies. Presented is the assessment of
\end{abstract}

the components of psychological readiness to the implementation of ICT through the respondents' free responses. The article revealed the criteria of psychological actualization of personal achievements in the use of ICT in professional activity. The conditions of psychological readiness for the use of ICTs in pedagogical activity as well as the professional tasks of ICT use were determined. The practical value of the study was the presentation of the recommended strategy for implementation of ICTwarehouses in professional activities with the use of information on the psychological readiness of the teacher.

Keywords-Information and communications technology, life-long learning, pedagogical practice, psychological readiness.

\section{INTRODUCTION}

Tn the digital age, the use of information and communications technology (ICT) in the General High School Educational Institution (GHSEI) is important to enable students to learn and apply 21 st century skills. ICTs improve teaching and learning systems and enhance the educational experience of educators in their role as creators of pedagogical environments. ICTs help teachers present their teaching and make it comprehensible to students at any level of the educational curriculum. 
New challenges for the teacher in this context are related to the independent selection and development of educational content and the modeling of the learning process in the context of the choice of virtualized alternatives in the ICT format. However, a significant proportion of teachers, through a range of circumstances (personal, professional, moral, material, sometimes gender), experience clashes of internal or external components of psychological barriers, negatively affect the implementation of practical knowledge about ICT in pedagogical activities and cause partial or complete cessation of such implementation. On this basis, the essence of the concept of psychological preparedness of teachers to implement professional digital activity in polysubjective educational environment requires analysis of its own structure of preparedness and its strategic importance for education in general and each individual teacher in particular.

In this way, the current problem is the inequality between the active implementation of innovations in education and the lack of psychological readiness of teachers to actively engage in innovation: active implementation of innovations in education and insufficient psychological readiness of teachers to actively engage in innovative activities, to adapt quickly to modern information changes; the importance of forming psychological readiness to use innovations and the lack of technology for forming such a phenomenon in the real practice of the general education institution; the broad potential of the informational and educational environment of the school and limited use of it as a means of shaping the psychological readiness to use innovations.

Consequently, the relevance of finding out the components of the psychological strategy for teachers' use of ICT in the GHSEI involves the category of cooperation, reflexive, motivational and informational parts of which are justified and characterized as components of teacher readiness for professional activity in a multisubject educational environment.

\section{LITERATURE REVIEW}

The use of information and communication technologies in education is changing the educational role of the teacher [1], which is why it is so important to understand that psychological preparation for working with new technologies must be at the highest level.

According to García-Valcárcel, \& Mena [2], information and communication technologies are often used as key tools to promote collaborative learning among teachers. Their use allows teachers to complete assignments, solve problems, or create products together. A critical implication for teacher education programs is to consider the actual limitations of teachers' knowledge and use of ICTs in practice to establish a more accurate starting point for facilitating collaboration through technology. Sydorenko, et al. describe that the intensity of ICT use in learning activities affects the development of elementary teachers' professional competencies [3]. Integrated learning in elementary schools requires teaching media as a means of communication, on this basis, comprehensive research is needed to analyze the use of media learning in elementary schools [4].

Hrehova \& Teplická [5] examine global perspectives on education and the role of ICT. The authors offer a balanced theoretical and research framework of the opportunities and potential benefits of information and communication technology to improve the quality of education, as advances in information and communication technology are both cause and effect of globalization. Batool, et al. [6] argue that information and communication technologies in pedagogy and teachers' psychological readiness to use them should be monitored by Departments of Education.

Michaeli, et al. [7] write that education dashboards are a way to present information to various stakeholders about those who are learning, most often by student activities in an online learning environment. Typically, education dashboards for teachers include certain types of visual aids that encourage teachers to reflect on and act on student behaviors. In practice, this tool can help teachers make data-driven decisions, thereby supporting their professional growth, but by this time the use of education dashboards by teachers has been little studied.

Andreevsky, et al. [8] Spivakovska [9] argue that the rethinking of modern information and communication technologies from teaching tools to the subjects of the educational process is based on the constant growth of their subjectivity, requires appropriate knowledge, skills, appropriate attitude to the didactic capabilities of ICT, the ability to cooperate with them and shape the learning activities of students to form and develop self-organization, selfdevelopment skills, promote their subjective position in obtaining education, will be the readiness of modern teachers to organize According to Almashi [10] and Kapalygina [11], psychological features of innovation management in the activities of the teacher when using information and communication platforms is the formation of their social position on innovation. The curriculum for teachers should update ICT knowledge using a comprehensive psychological approach to them because, according to Rani [12], planning the integration of technology in teacher education, it is important that teacher education, institutions, higher education institutions (HEIs) understand the knowledge and skills necessary for teachers to effectively use ICT in their work. Oralbekova, et al. [13] point out that it is important to form future preschool teachers' readiness to use information and communication technologies in inclusive education. The authors justify the need for the formation of students' abilities in modern ICT-sphere. Transmedia technology, in this context, as defined by Havrilova, et al. [14] is a modern innovative system, which scientists consider a real communication revolution. Shakhbanova \& Yarmetov [15] in their article consider the information and communication technology used in business processes presented to work effectively in the learning process, teacher with students based on Bitrix 24 and Planfix management system. Letendre [16] in this context 
describes ICT in the context of world culture and sociology of education. The relevance of digitalization of education is justified by Negriy \& Lagutin [17] and Selivanova, et al. [18], citing economic, technological and psychological reasons for this process in modern society.

Hence, despite the extensive review presented in the context of the topic at hand, the structure of the GHSEI teacher's psychological readiness strategy for using ICT in their activities remains poorly explored.

The purpose of this article is to provide a pedagogical strategy for developing teachers' psychological readiness to use ICT to eliminate internal and external barriers that interfere with the intensive exchange of information within and behind the educational team. Research tasks:

- to conduct a sociological survey among GHSEI teachers to identify the elements of the strategy of psychological readiness to use ICT in professional activities;

- to make recommendations for implementation of the strategy in professional activities.

\section{METHODS}

The research presents the results of a sociological survey conducted GHSEI teachers (Ukraine). To conduct a survey, teachers were asked to take a survey using the online service "Online Test Pad". This multifunctional service for testing made it possible to use tests with single selection, multiple selection, as well as in the form of matrices with the ability to enter text, answer questions in any form. The obtained answers were processed in the context of each result, as well as statistics of answers to each question. The answers to the questions were stored in the form of Excel spreadsheets.

The obtained results of the questionnaire were processed in order to obtain conclusions about the psychological readiness of teachers to use ICT in their professional activities. The number of participants who took part in the survey and questionnaire -1200 respondents from different regions of Ukraine. Sphere of employment of respondents: education, pedagogical activity. Related fields in which the interviewed teachers are employed: computer science and psychology. The total duration of the study is up to 5 months.

Stages of the study:

1) development and of the questionnaire content;

2) random sampling of respondents using educational online resources;

3) distribution of the questionnaire to the participants' reviewed electronic screenshots with the deadline set for the answer;

4) evaluation of the answers, collection of results;

5) start of automatic statistics in the form of graphs and tables;

6) processing of received data;

7) presentation of the research result part.

\section{RESULTS}

Respondents had the task to assess their own pedagogical training when they themselves were still students and to rank the constituent elements in the structure of psychological readiness of students to implement educational innovations. The results are distributed as follows: emotional-motivational, cognitive-targeted, orientational, activity-operational, moral, communicative, volitional, mobilizational, and evaluationresulted; each received $78 \%, 85 \%, 45 \%, 92 \%, 47 \%, 41 \%$ $63 \%, 51 \%, 97 \%$ respectively. The results are shown in Fig. 1.

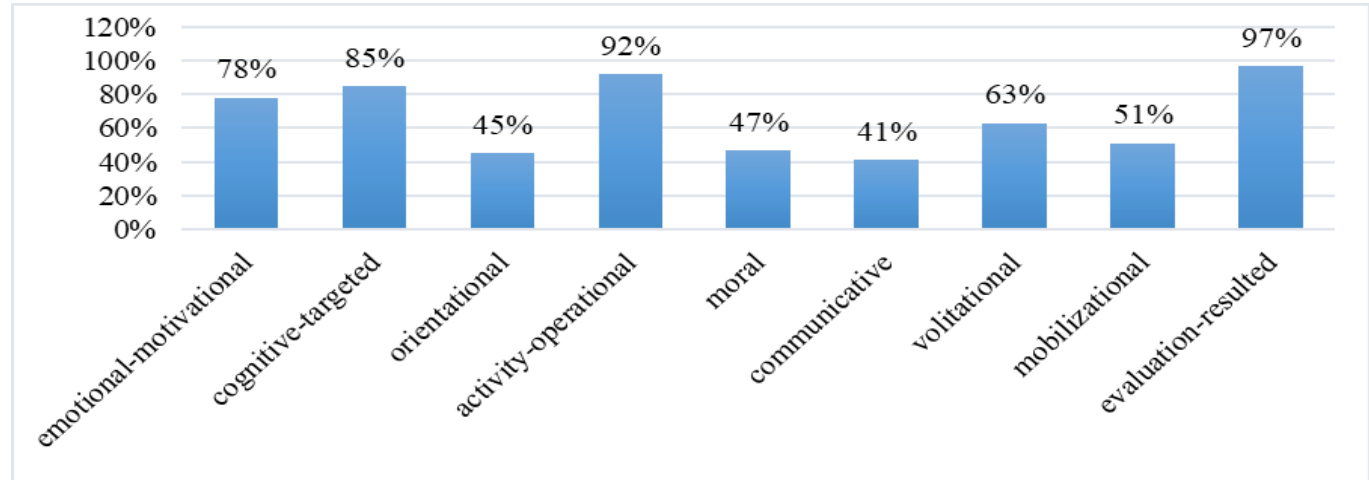

Fig. 1 Constituent elements in the structure of students' psychological readiness to implement educational innovations Source: questionnaire data

In order to introduce different forms and methods of work to overcome the main psychological barriers to innovation in the use of information and communication technologies, respondents in a free statement of the questionnaire suggested stages of successive psychological preparation for their implementation. The author reduced them to the following format: the first stage was the initiation of innovation ( $86 \%$ of respondents wrote about it). The second stage involves presentation of the innovation to the group or team. This stage is important for $97 \%$ of the responses. The third stage is "Discussion". It was used by all respondents. The fourth stage is described by $56 \%$ of respondents. It involves approbation with psychological counseling by a specialist. At the last stage, $72 \%$ of participants offered a second discussion. The results 
are presented in Fig. 2.

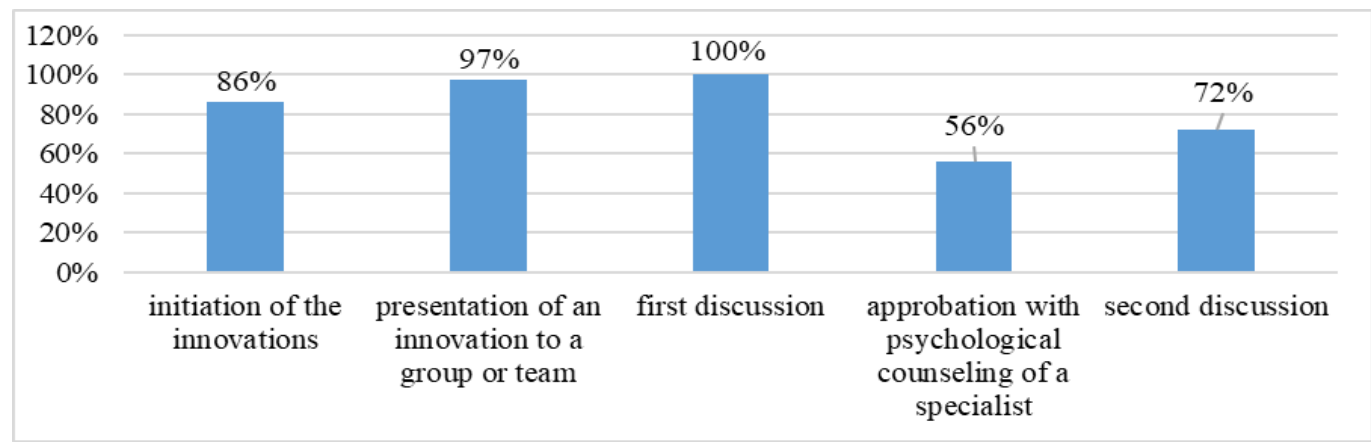

Fig. 2 Stages of sequential psychological preparation for the introduction of ICTs

Source: questionnaire data

In the free field of the questionnaire, respondents were asked to state their vision of the components of psychological readiness for ICT implementation. The author reduced the definition as follows. The receptive component, according to $78 \%$ of respondents, is the presence of knowledge in the field of information technology about the opportunity to implement educational potential. The reproductive component (most involved in the psychological aspect), according to $87 \%$ of respondents, is the presence of positive motivation to use information technology in professional activities. In the opinion of $54 \%$ of respondents, the productive component is the formation of a system of skills and abilities to use information technology in teaching. The last, creative component, selected by only $31 \%$ of the respondents, is the realization of potential in the process of using information technologies in professional activity. The results are shown in Fig. 3.

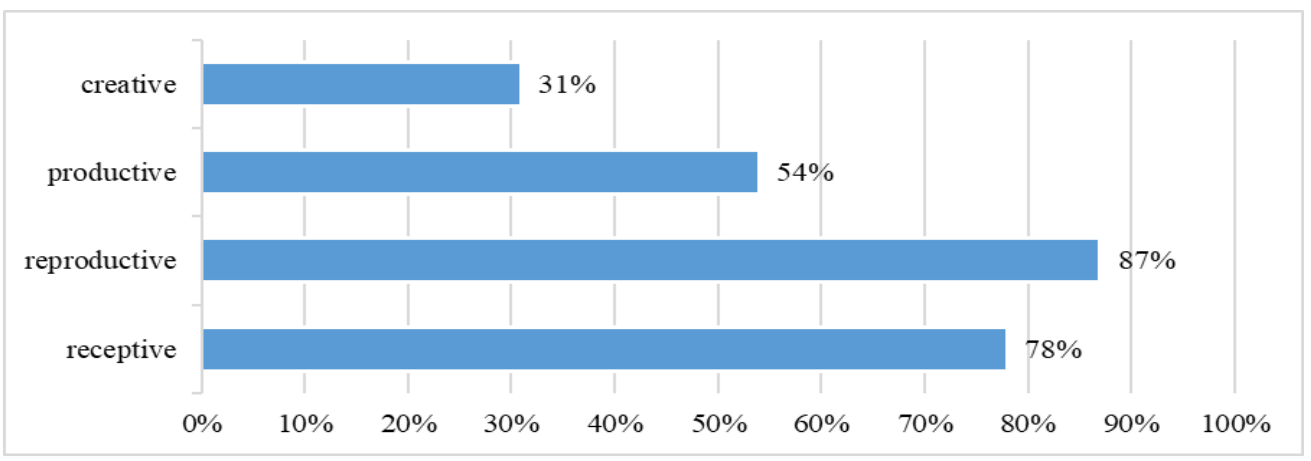

Fig. 3 Self-view of the components of psychological readiness for ICT implementation

Source: questionnaire data

The survey participants also determined that the criteria of psychological actualization of personal achievements in ICT use in professional activity are: meaningfulness of own achievements in ICT use in professional activity ( $83 \%$ of answers); interest in own achievements in effective ICT use
(75\% of answers); practical readiness to implement real actions towards high achievements in ICT use in professional activity ( $71 \%$ of answers); aspirations to increase achievements. The results are presented in Fig. 4.

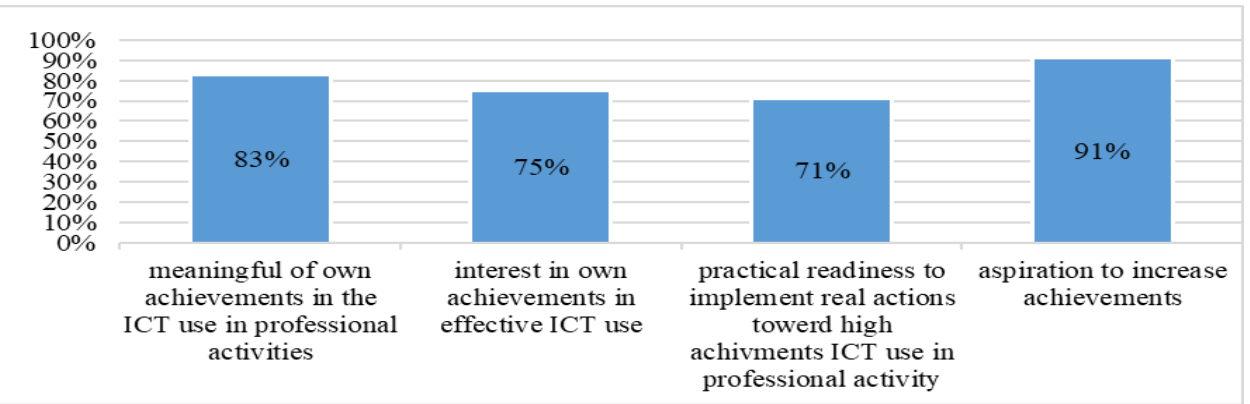

Fig. 4 Criteria of the psychological actualization of personal achievements in the use of ICT in professional activities Source: questionnaire data 
In the free field of the questionnaire respondents were asked to identify the conditions of psychological readiness for ICT application in pedagogical activity. The results were presented as follows: organic combination of the process of development of professional qualities, knowledge and skills with the process of computer science learning; integration of self-education in computer science with profile courses of professional content; inclusion of professional tasks requiring heuristic search for solution using computer and professional knowledge into the content of self-education in computer science, which is based on the problem approach; realization of interdisciplinary links by using ICT in preparation and carrying out the numerical indicators the author reduced to such percentages: $35 \%, 28 \%$, $17 \%, 10 \%, 10 \%$. The results are presented in Fig. 5 .

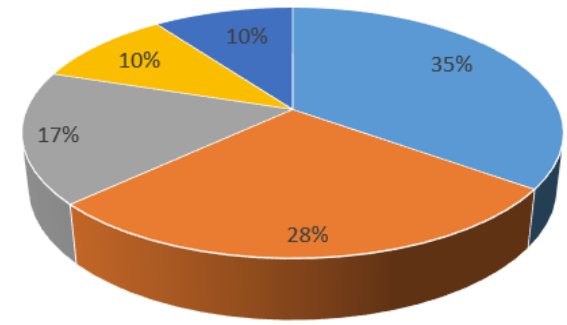

- organic combination

- integration of self-education

- inclusion of professional tasks

- realization of interdisciplinary links

- visual comparison of the implementation of pedagogical technologies

Fig. 5 Conditions of psychological readiness to use ICT in pedagogical activity

Source: questionnaire data

Under these conditions of shaping the teacher's readiness and ability to use ICT in their professional activities, the respondents were asked to determine which tasks could be solved in the context of the proposed conditions. The results are presented in Fig. 6.

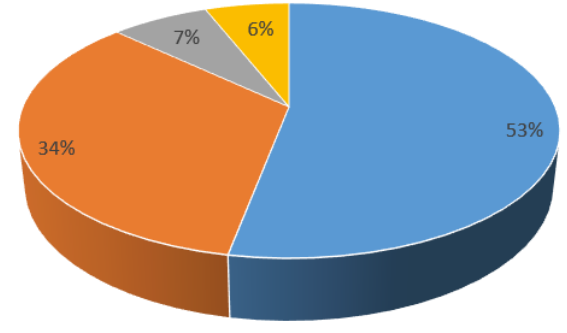

- improvement and development of personal computer skills

- familiarization with general and educational software

- mastering the methods of teaching professional disciplines using ICT

- development of skills and abilities to work with electronic information

Fig. 6 Professional tasks of ICT application

Source: questionnaire data
Improvement and development of personal computer skills, peripheral devices, local and global networks were in the first place with a score of $53 \%$; familiarization with general and educational software, modeling environments, and possibilities of their use in the learning process (34\%); mastering the methods of teaching professional disciplines using ICT (7\%); development of skills and abilities to work with electronic information (search, analysis, systematization $(6 \%)$.

Thus, the psychological readiness of a GHSEI teacher to use ICTs should encompass such actions as possessing the skills to organize instruction using ICTs, knowing the possible rational and most effective ways, being able to combine them and adapt them to the needs of a particular audience.

\section{DISCUSSION}

In our study it is important to rely on the understanding of the concept of "transmedia technology". We find it in the works of world scientists. Transmedia technology is studied and actively implemented in various spheres of life and social activities, such as media, journalism, marketing, culture, education, and the like. The introduction of transmedia technology in the professional training of teachers contributes to the qualitative development of their professional competence, broadening their horizons, improving their artistic abilities and professional skills [14].

Data from a study by Ibieta, et al. [19] in Chile indicate that teachers' use of information and communication technology in the classroom is still limited in variety and frequency in Chile. Multiple regression analyses were applied to determine the relationships between them. Findings indicate, first, that teachers are more likely to use ICTs outside the classroom for classroom preparation; second, that their perception of the impact of ICTs on professional practice is a major factor related to their use of ICTs inside and outside the classroom; third, that less experienced teachers are more likely to use communication tools with colleagues and students; and finally, that teachers' use of (off-the-rack) Internet resources should be examined.

But Kravchuk [20] defines the psychological readiness of student youth to implement educational innovations as an integrative formation that combines the manifestation of individual, personal, subjective characteristics in their integrity, the presence of functional and personal readiness of the person to implement educational innovations, which is due to the presence of a certain psychological attitude to achieve the expected result, the dominant motives and orientation. In the structure of psychological readiness of student youth to implement educational innovations it is advisable to identify the following components: emotional-motivational, cognitivetarget, orientation, activity-operational, moral, communicative, volitional, mobilization, evaluation-result. The respondents of our study fully confirmed the presence of all the defined components.

The use of ICT, such as social media platforms, software 
applications, software and cloud messenger, enhances teachers' online competencies and expands the range of professional competencies. Ongoing modernization of learning content based on Twitter, Telegram, Facebook, etc. should be promising for building key and professional competencies and increasing motivation in primary education teacher training [3].

In educational institutions, Punjab is a prerequisite for the professional application of ICT in several areas of society [21]. Gupta [22] offers the view that today's teachers have to update their knowledge and skills as school curricula and technology change rapidly. The transition from blackboard to smart classrooms has changed the aspect of modern teaching. Information and communication technology (ICT) can significantly support the education system if the teacher is competent enough to use the tools. To this end, the curriculum of the teacher education system also contributes to the training of future teachers. Delhi and National Capital Region (NCR) attempted to investigate the issue of psychological readiness for the proposed innovations and concluded that the inclusion of ICT component in the preparation of new teacher curriculum in the context of psychological vector is a must. Ponmozhi [23] investigated the need for information communication technology among educators in Cuddalore district in Tamil Nadu. Most educators experience a lack of psychological counseling when working with new ICT tools. Ratheeswari [24] investigating the impact of ICT on teacher education in India, concluded that the Internet and interactive multimedia is clearly an important area of future education and needs to be effectively integrated into formal teaching and learning - especially in the teacher education setting. Akhy \& Iswari [25], working over an analysis of the topic in Morocco, determined that the availability of multimedia resources, tips for their use, and knowledge of how ICTs become tools for development may not be worthwhile if the psychological factor of working with them is not considered. Yusop, et al. [26], Graham, et al. [27] argue in their writings that Planned Behavior Theory is a valid model to explain Indonesian educators' use of information and communication technology during teaching practice. The scientific exploration of Robertson, et al. [28] present that Proactive Behavior Management (PBM) improves the behavior of students with and without disabilities, yet teachers rarely use such strategies. One obstacle to the implementation of PBM is teachers' beliefs contradicting a proactive approach to behavior management in favor of a punitive approach. The work of Drossel, et al. [29] and a study conducted in 5 countries (Netherlands, Denmark, Australia, Poland, and Germany) is based on the research question of what predictors (school characteristics, teacher attitudes, teacher collaboration, and general characteristics) determine the frequency of a middle school teacher's use of a computer in the classroom. Middle school teachers' use of new technology for instructional purposes is an important factor in school and instructional processes. The use of digital media in schools, among other things, is related to the purpose of supporting learning processes and improving the quality of education to gain insight on how to support the frequency of computer use in the classroom. Ferreira, D. [30], exploring the experiences of university English as a Foreign Language (EFL) teachers in East Japan explored tactics to overcome barriers to integrating information and communication technology into their daily teaching practices. It was determined that neither the computer, projector, nor the Internet were the barriers to ICT integration Complex instructional software was a barrier to ICT integration and student teaching learning objectives/gives valid solutions for successful ICT integration. Recommendations for educational leadership included equipping each classroom with a computer/projector connected to the Internet and ensuring regular maintenance of these devices, providing reliable $\mathrm{Wi}-\mathrm{Fi}$ to improve ICT implementation, creating a theory-driven ICT curriculum tied to learning objectives of the curriculum.

We agree that such thoughts should also be supported by the legal framework in the area in question.

\section{CONCLUSION}

Hence, based on the conducted research and thematic literature analysis, we attempt to make recommendations for the implementation of ICT strategy in professional activity by using information on psychological readiness of a teacher and such implementation.

The psychological process of preparing future teachers to use ICTs in professional activities should be implemented through:

- actualization of subjective position of a teacher's personality in the process of his/her preparation for ICT use in professional activity;

- psychological flexibility of management and selfmanagement of such training process;

- psychological modular technology for structuring educational material for studying theoretical and practical aspects of ICT use in a teacher's professional activity.

- systematic unification and interconnection of the following elements:

1) motivational (expressed by interests and needs for the use of information and communication technologies, the desire for professional self-improvement in the application of information and communication technologies in future teaching activities, the desire to acquire knowledge, skills and user skills in ICT to the use of standard and special software and hardware for educational purposes);

2) cognitive, providing a set of subjects, methodological and technological knowledge, which integrates general and special knowledge in the use of information and communication technologies in secondary general education, that is, knowledge of the basics of ICT capabilities of using basic software and hardware at the user level, and for their application in educational purposes; knowledge of the possibilities of using instrumental software tools in professional activities, etc.; 
3) operational and technological, a pronounced set of skills for organizing the training of students using information and communication technologies.

We recommend to pay special attention to the development of personal position, increasing the significance of the experience of using ICT in professional activity by actualizing subjective position through stimulation of personal achievements; creating problem situations in the training process; involvement in personally meaningful activities for them.

The pedagogical strategy for the development of teachers' psychological readiness to implement ICTs is recommended to be implemented in three directions. The first direction is related to the expansion of ideas of the heads of general educational organizations about the measures to encourage teachers to share knowledge. The second direction of the strategy is the formation of a favorable climate in the team, stimulating formal and informal communication of teachers. The third direction is focused on the development of teachers' motivation for self-improvement through exposure to positive practices of pedagogical success.

Thus, for successful implementation is a sound pedagogical strategy for the development of teachers' psychological readiness to use ICT, it is necessary to make the removal of internal and external barriers to the intensive exchange of information inside and outside the teaching staff, using the recommendations given.

An important direction for further research will be an attempt to identify additional barriers that suspend or completely stop the implementation of ICT in pedagogical activities.

The practical significance of the study was the presentation of the recommended strategy for the implementation of ICT strategy in professional activities using information on the psychological readiness of the teacher.

\section{References}

[1] H. Petrova, "New functions of teachers when training with information-communication technologies", New technologies in Physics Education, 25, 2016, pp. 786-790, https://www.researchgate.net/publication/309811744_Ne w_functions_of_teachers_when_training_with_informatio n-communication_technologies

[2] A. García-Valcárcel, J. Mena, "In-service teachers' use of ICT for the promotion of collaborative professional learning", Research anthology on facilitating new educational practices through communities of learning, 1, 2021, pp. 287-301, https://doi.org/10.4018/978-1-79987294-8.ch015

[3] N. Sydorenko, V. Denysenko, N. Borisenko, I. Hrytsenko, "Formation of professional competencies of primary school teachers using ICT", Revista Tempos e Espaços em Educação, 13, 2020, pp. 1-17, https://doi.org/10.20952/revtee.v13i32.14965

[4] R. Hidayah, T. Susiani, \& M. Salimi, "How elementary school teachers use ICT-based learning media?". Journal of Physics: Conference Series, 1511, 2020, pp. 012-015. https://doi.org/10.1088/1742-6596/1511/1/012015

[5] D. Hrehova, K. Teplická, "The informational communication technology is a tool of globaleducation", SHS Web of Conferences, 74, 2020, pp. 06-08. https://doi.org/10.1051/shsconf/20207406008

[6] A. Batool, H. Kazmi, R. Islam, M. Nawaz, "Effects of Using ICT in Professional Development", Merit Research Journal of Education and Review, 8, 2021, pp. 001-005, https://doi.org/10.5281/zenodo.3620848

[7] S. Michaeli, D. Kroparo, A. Hershkovitz, "Teachers' use of education dashboards and professional growth", The International Review of Research in Open and Distributed Learning, 21, 2020, pp. 61-78, https://doi.org/10.19173/irrodl.v21i4.4663

[8] E. Andreevsky, M. Akhmedkhanov, T. Lavina, R. Streltsov, "Improving professional and psychological selection and further development of professionally important qualities of specialists on the protection of important state facilities in the course of educational activities with the use of information and communication technologies", Procedia - Social and Behavioral Sciences, 214, 2015, pp. 497-504, https://doi.org/10.1016/j.sbspro.2015.11.749

[9] Y. Spivakovska, "Psychological strategy of cooperation, motivational, information and technological components of future humanitarian teacher readiness for professional activity in polysubjective learning environment", Information Technologies in Education, 1, 2014, pp. 111121, https://doi.org/10.14308/ite000474

[10] I. Almashi, "Psychology of innovation management using information and communication technologies in the activities of environmental public organizations", Scientific Bulletin of Mukachevo State University, 2(10), 2019, pp. 105-107. https://doi.org/10.31339/2413-33292019-2(10)/2-105-107

[11]I. Kapalygina, "Development of information hazard awareness in primary school learners through due structuring of pedagogical activities", Perspectives of Science and Education, 50, 2021, pp. 243-255. https://doi.org/10.32744/pse.2021.2.17

[12] R. Rani, "ICT (Information Communication Technology) in Teacher Education", Shikshan Anveshika, 7, 2017, https://doi.org/10.5958/2348-7534.2017.00025.3

[13] A. Oralbekova, S. Begalieva, A. Ortaeva, A. Magauova, M. Suleimen, "Teachers' readiness to use ICT in the conditions of inclusive education", E3S Web of Conferences, 258, 2021, pp. 07-21, https://doi.org/10.1051/e3sconf/202125807021

[14] 14., L. Havrilova, , V. Oriekhova, , O. Beskorsa, , O. Churikova-Kushnir, Z. Sofronii, "A survey analysis of art teachers' use of transmedia technology", Multidisciplinary Journal for Education, Social and Technological Sciences, 8, 2021, pp. 58. https://doi.org/10.4995/muse.2021.14875

[15]Z. Shakhbanova, Z. Yarmetov, "Improving the effectiveness of teachers using ICT", Ekonomika I Upravlenie: Problemy, Resheniya, 4, 2020, pp. 42-50, https://doi.org/10.36871/Ek.Up.P.R.2020.11.04.008 
[16] G. Letendre, "World Culture, Educational Sociology and the Impact of Information \& Communication Technology on Teachers", The Journal of Educational Sociology, 100, 2017, pp. 60-69. https://doi.org/10.11151/eds.100.60

[17] V. Negriy, G. Lagutin, "Psychological aspects of digitalization of education", Safety psychology and psychological safety: problems of interaction between theorists and practitioners, 14, 2020, pp. 199-205, https://doi.org/10.15862/53MNNPK20-26

[18]E. Selivanova, N. Yarychev, D. Ilyasov, "Pedagogical strategy for developing teachers' psychological readiness to exchange knowledge". International Technology, Education and Development Conference, 2020, pp. 21192126, https://doi.org/10.21125/inted.2020.0663

[19] A. Ibieta, J. Hinostroza, Ch. Labbé, M. Claro, "The role of the Internet in teachers' professional practice: activities and factors associated with teacher use of ICT inside and outside the classroom", Technology, Pedagogy and Education, 26, 2017, pp. 1-14. https://doi.org/10.1080/1475939X.2017.1296489

[20] S. Kravchuk, "Peculiarities of psychological readiness of student youth of pedagogical specialties for introduction of educational innovations", Scientific Bulletin of Kherson State University. Series Psychological Sciences, 12, 2020, pp. 147-154. https://doi.org/10.32999/ksu23123206/2020-3-18

[21] N. Malik, I. Baig, R. Minas, "Application of Information Communication Technology at Secondary School Level and Its Practices", Global Educational Studies Review, 6, 2021, pp. 253-260, https://doi.org/10.31703/gesr.2021(VI-I).26

[22]D. Gupta, "Teacher Education Curriculum in context of Information \& Communication Technology", Issues and Ideas in Education, 3, 2015, pp. 85-101. https://doi.org/10.15415/iie.2015.32007

[23] D. Ponmozhi, "Information Communication Technology Still Need For Teacher Educators", International Journal of Scientific and Research Publications (IJSRP), 1, 2018, https://doi.org/10.29322/IJSRP.8.10.2018.p8212

[24]K. Ratheeswari, "Information Communication Technology in Education", Journal of Applied and Advanced Research, 3, 45, 2018, https://doi.org/10.21839/jaar.2018.v3iS1.169

[25]K. Akhy, W. Iswari, "Information Communication Technology in EFL Classroom", Journal of English as A Foreign Language Teaching and Research, 1, 2021, pp. 61-70, https://doi.org/10.31098/jefltr.v1i1.485

[26]F. Yusop, A. Habibi, R. Abdul Razak, "Factors affecting Indonesian preservice teachers' use of ICT during teaching practices through theory of planned behavior". SAGE Open, 11, 2021, https://doi.org/10.1177/21582440211027572

[27] M. Graham, G. Stols, R. Kapp, "Teacher practice and integration of ICT: why are or aren't South African teachers using ICTs in their classrooms", International Journal of Instruction, 13, 2020, pp. 749-766. https://doi.org/10.29333/iji.2020.13251a
[28] R. Robertson, K. Buonomo, H. Abdellatif, S. DeMaria, "Results of a "Psychologically Wise" professional development to increase teacher use of proactive behavior management strategies", Psychology in the Schools, 1, 58, 2021, https://doi.org/10.1002/pits.22526

[29] K. Drossel, B. Eickelmann, J. Gerick, "Predictors of teachers' use of ICT in school - the relevance of school characteristics, teachers' attitudes and teacher collaboration", Education and Information Technologies, 15, 2017, p. 22, https://doi.org/10.1007/s10639-0169476-y

[30]D. Ferreira, "Barriers to teacher use of technology for teaching", Japan Association of Language Teaching Online Conference, 2020, https://doi.org/10.13140/RG.2.2.26416.58888

Creative Commons Attribution License 4.0 (Attribution 4.0 International, CC BY 4.0)

This article is published under the terms of the Creative Commons Attribution License 4.0 https://creativecommons.org/licenses/by/4.0/deed.en_US 